\title{
AMBIÊNCIAS FORMATIVAS EM TEMPO DE NOVAS EDUCAÇÕES: O QUE APRENDEMOSENSINAMOS COM A PANDEMIA
}

\author{
Luis Henrique Monteiro de Castro ${ }^{\mathrm{i}}$ \\ Rosemary dos Santos ${ }^{\text {ii }}$
}

\begin{abstract}
Resumo: $\mathrm{O}$ artigo se propõe a investigar e mapear algumas práticas de aprendizagemensino com o uso da mediação tecnológica em rede no cotidiano de um grupo de alunos no componente curricular Eletrônica Digital de uma Escola Técnica do Rio de Janeiro durante um período da pandemia da COVID-19. As atividades foram desenvolvidas com o uso de Ambiente Virtual de Aprendizagem e de interfaces de web conferência. Ao trazermos como dispositivos de pesquisa o WhatsApp e o Moodle encontramos nas conversas a possibilidade de articulação e ressignificação de novas práticas cotidianas nos espaços e nos tempos escolares e constatamos que o atendimento remoto possui suas potencialidades comunicacionais e educativas, mas não substituirá as aulas presenciais que precisarão ser retomadas após este tempo de pandemia.
\end{abstract}

Palavras-chave: Aprendizagem; COVID-19; Educação tecnológica

\section{FORMATIVE ENVIRONMENTS IN TIME FOR NEW EDUCATIONS: WHAT WE LEARNED FROM THE PANDEMIC}

\begin{abstract}
The article proposes to investigate and map some teaching learning practices with the use of technological mediation in the daily routine of a group of students in the Digital Electronic curriculum component of a Technical School in Rio de Janeiro during a period of the COVID19 pandemic. The activities were developed using the Virtual Learning Environment and web conferencing interfaces. By bringing WhatsApp and Moodle as search devices, we found in the conversations the possibility of articulating and reframing new daily practices in school spaces and times and we found that remote care has its communicational and educational potential, but it will not replace the face-to-face classes that will need to be resumed after this pandemic time.
\end{abstract}

Keywords: Learning; COVID-19; Technology education

\section{INTRODUÇÃO}

O enfrentamento da pandemia da COVID-19 impôs aos Sistemas de Educação de todo o mundo uma nova dinâmica. No período entre 28 de março e 26 de abril, a evolução da pandemia fez com que inúmeras unidades educacionais fechassem as suas portas, afetando cerca de 1,7 bilhões de alunos - 90\% de todos os estudantes do mundo (UNESCO, 2020). Em cerca de 193 países, alunos de diferentes faixas etárias e de diferentes níveis de escolaridade tiveram as suas rotinas modificadas, seja por medidas de isolamento social ou de fechamento total de cidades, estados e países. A UNESCO estima que boa parte dos estudantes ficou impedia de frequentar o ambiente escolar por aproximadamente um mês (UNESCO, 2020). 
No Brasil, as medidas foram variadas, mas os resultados, semelhantes. No estado do Rio de Janeiro, os alunos matriculados nas unidades educacionais (creches, escolas, colégios, faculdades e universidades) deixaram de frequentar fisicamente o ambiente escolar na segunda quinzena de março devido à determinação do inciso VI do artigo $4^{\circ}$ do Decreto Estadual $n^{\circ} 46.980$ de 19 de março de 2020:

Art. $4^{\circ}$ De forma excepcional, com o único objetivo de resguardar o interesse da coletividade na prevenção do contágio e no combate da propagação do coronavírus, (COVID-19), diante de mortes já confirmadas e o aumento de pessoas contaminadas, DETERMINO A SUSPENSÃO, pelo prazo de 15 (quinze) dias, das seguintes atividades:

VI - aulas, sem prejuízo da manutenção do calendário recomendado pelo Ministério da Educação, nas unidades da rede pública e privada de ensino, inclusive nas unidades de ensino superior, sendo certo, que o Secretário de Estado de Educação e o Secretário de Estado de Ciência, Tecnologia e Inovação deverão expedir em 48 (quarenta e oito horas) ato infralegal para regulamentar as medidas de que tratam o presente Decreto, bem como, adotar medidas para possibilitar o ensino a distância.

A determinação de suspensão temporária das atividades escolares foi reafirmada, sucessivamente, nos Decretos publicados pelo executivo estadual em 27 de março - Decreto $\mathrm{n}^{\mathrm{o}}$ 47.006, em 13 de abril - Decreto no 47027, em 29 de abril - Decreto n ${ }^{\circ} 47052$, em11 de maio Decreto $n^{\circ} 47068$ e em $1^{\circ}$ de junho - Decreto $n^{\circ} 47.102$.

Como consequência, quase imediata, ao primeiro Decreto Estadual, a Presidente do Conselho Estadual de Educação do Rio de Janeiro, com anuência da Comissão de Planejamento do Conselho Estadual do Rio de Janeiro, publicou a Deliberação CEE No 376, no dia 23 de março, orientando as Instituições integrantes do Sistema Estadual de Ensino do estado do Rio de Janeiro sobre o desenvolvimento das atividades escolares não presenciais, em caráter de excepcionalidade e temporalidade, enquanto permanecerem as medidas de isolamento previstas pelas autoridades estaduais na prevenção e combate ao novo corona vírus (SARS-CoV-2).

Porém, apenas no dia $1^{\mathrm{o}}$ de junho de 2020, o Parecer do Conselho Pleno/Conselho Nacional de Educação que versa sobre a Reorganização do Calendário Escolar e da possibilidade de cômputo de atividades não presenciais para fins de cumprimento da carga horária mínima anual, em razão da Pandemia da COVID-19 de 28 de abril (CNE, 2020), foi homologado pelo senhor Ministro da Educação (BRASIL, 2020). Cabe registrar que a Lei $n^{\circ}$ 4.024, de 20 de dezembro de 1961, alterada pela Lei $\mathrm{n}^{\mathrm{o}}$ 9.131, de 24 de novembro de 1995, delega ao CNE competência para estabelecer orientações e diretrizes sobre a reorganização dos calendários escolares no país. Desta forma foi criada, durante quase três meses, uma insegurança normativa quanto ao resultado das ações das atividades de educação não presencial no Brasil. 
Com base nesta realidade, em escolas públicas e em escolas privadas, alunos e professores viveram, e ainda vivem, uma realidade ímpar repleta de incertezas e angústias na qual há uma bricolagem do ambiente privado de professores e alunos com o ambiente público da Escola (CERTEAU, 2014). De maneira repentina, se tornou imprescindível um novo planejamento nas escolas utilizando massivamente novas táticas educacionais para buscar atenuar as inevitáveis consequências que a pandemia provocaria na educação de todo o país. Neste contexto educacional, este artigo se propõe a investigar e mapear algumas práticas de aprendizagemensino $^{i i i}$ com o uso da mediação tecnológica em rede no cotidiano de um grupo de alunos da componente curricular Eletrônica Digital de uma Escola Técnica na Zona Norte do Rio de Janeiro durante um período da pandemia da COVID-19.

\section{EDUCAÇÕES, REDES EDUCATIVAS E PRÁTICAS COTIDIANAS}

A urgência de retomar as atividades escolares, mantendo a intervenção pedagógica centralizadas na presença do professor e orientada por conteúdos - a despeito dos efeitos nocivos do avanço da doença, do aumento exponencial e diário do número de mortos e da própria restrição do convívio social - fez as redes de escolas públicas e privadas do estado do Rio de Janeiro iniciaram variadas ações educativas. Quase todas as ações mediadas através de tecnologia foram iniciadas de forma improvisada e sem planejamento. Dentre elas, podemos destacar a proposta pedagógica adotada por grande parte da Rede Privada de ensino, a simples transferência da rotina escolar presencial para o ambiente web, com o uso de conferências síncronas, isto é, contemplando a comunicação de áudio e vídeo em tempo real, e obedecendo os horários e muitas vezes também as práticas tradicionais. Sem uma preparação prévia e adequada dos docentes, a sala de aula com mediação tecnológica reproduz "o lugar do discurso racionalista, redutor e disciplinar que se (re)afirma a partir do discurso da autoridade, esquecendo a importância da autoridade do argumento na construção do conhecimento" (SIQUEIRA, 2003, p. 191) já vivido nas salas presenciais.

Conforme apontam Ribeiro, Carvalho e Santos R. (2018), esse modelo de formação, já na modalidade presencial, impossibilitava aos praticantes ${ }^{\text {iv }}$, o desenvolvimento da capacidade de tornar-se seu coautor, ou seja, a fazer a diferenciação, a ter uma escuta diferenciada do outro que nos habita, que está em nós. A autoria é, na perspectiva que dialogamos, um encontro com a diferenciação de si e dos outros. Só seremos alguém se conseguirmos dialogar com esses outros que estão dentro de nós. 
Essa rotina se revela, em muitos dos casos, um arremedo pedagógico, baseada na mudança da exposição oral presencial para a repetição à distância das explicações e exercícios, restritas aos dias e hora previamente marcados. Tudo isso, que se repete a cada componente curricular no caso dos alunos e a cada turma no caso do professor, tem gerado desgaste a ambos. O esgotamento e patologias psicológicas estão sendo criadas (SANTOS, 2020). Esse contexto de educação formal síncrona ou ensino remoto em tempo real só se mostrou minimamente viável nas escolas particulares, visto que boa parte dos alunos dispunham de acesso aos dispositivos e aos planos de dados, instrumentos que a tempos já faziam parte do cotidiano dessas famílias.

Já nas escolas públicas brasileiras, em todos os segmentos, boa parte dos alunos não usufruem desses meios e equipamentos, cada vez mais custosos com a economia em declínio. Esta situação é evidenciada na pesquisa TIC-Domicílios, na qual apenas 39\% brasileiros afirmam possuir, em seus domicílios, computador e acesso à internet (CGI.br, 2018). A implementação de uma ação baseada nas atividades síncronas, como as empregadas nos colégios particulares, estaria, deste modo, na contramão das tendências democratizantes e de valorização das diferenças presentes em parte significativa da legislação e políticas para educação superior e básica públicas nos últimos anos. A obrigatoriedade de aulas, atividades e avaliações que prescrevam o uso de equipamento e planos de dados caros excluiriam boa parte dos alunos do processo de formação, fazendo da evasão a norma.

Pensando em ultrapassar esse fosso de desigualdade e exclusão, diretores e professores têm tentado desenvolver objetos, práticas e rotinas educacionais que se revelem mais democráticas e inclusivas. Apesar das medidas políticas tomadas para difundir uma situação planejada e controlada do atendimento educacional remoto, sem o apoio efetivo das secretarias de educação, é possível afirmar que, em analogia ao que Certeau (2014, p. 86) aponta, os professores, por falta de formação e equipamentos necessários, empregam, constroem, em muitos casos, "gambiarras", ao fazerem uso das mais variadas redes e apps, sobretudo, aquelas que já estão a mão e que cabem no bolso de muitos, para a obtenção de melhores resultados na educação em tempos de pandemia.

Nessa conjuntura, o uso conjunto de dispositivos, de aplicativos e de objetos educacionais presentes no dia a dia dos jovens e adultos parece ser fundamental para favorecer o processo de aprendizado desses jovens e adultos que, apesar de possuírem muita intimidade com as mídias e redes sociais, não têm acesso nem desenvoltura com os ambientes virtuais de aprendizagem tradicionais. 


\section{O MOVIMENTO PRATICATERORIAPRATICA E AS MÚLTIPLAS REDES DE}

\section{SABERES}

Diante dessa urgência política, social e educacional, enquanto professor da componente curricular de eletrônica digital de uma Escola Técnica da zona norte do município do Rio de Janeiro, lotado em curso de modalidade subsequente e pesquisador da cibercultura, buscamos levar novas metodologias e objetos educacionais acessíveis aos alunos. A primeira ação realizada foi a busca de contato remoto entre os alunos para criação de um grupo em uma rede de mensagens instantânea. Esse grupo foi fundamental para o estabelecimento de um primeiro contato em rede e para a escolha unânime da aplicação de mensagens WhatsApp para a utilização de todos e para os informes da componente curricular e das ações educacionais que seriam desenvolvidas.

Posto que o curso na modalidade subsequente da Escola não possuía uma plataforma que atendesse os alunos de forma institucional antes da pandemia, em 06 de abril, foi implementado um Ambiente Virtual de Aprendizagem, denominado de "AVA Subsequente". Utilizamos o ambiente Moodle com o objetivo de disponibilizar aos alunos e professores uma interface estruturada de interação educacional que possibilitasse o ensino remoto em tempos e espaços variados. Um recurso importante como afirma Santos:

\footnotetext{
Os AVA agregam uma das características fundantes da internet: a convergência de mídias, ou seja, a capacidade de hibridizar e permutar num mesmo ambiente várias mídias. Mídia é todo o suporte que veicula a mensagem expressada por uma multiplicidade de linguagens (sons, imagens, gráficos, textos em geral). Em alguns casos suporte e linguagem se hibridizam. Em outras palavras, é a união das tecnologias informáticas e suas aplicações com as telecomunicações e com as diversas formas de expressão e linguagens. Os ambientes virtuais de aprendizagem envolvem não só um conjunto de interfaces para socialização de informação, de conteúdos de ensino e aprendizagem, mas também, e, sobretudo, as interfaces de comunicação síncronas e assíncronas (2009, p. 5664).
}

Cabe ressaltar que, devido a pandemia, não houve nenhuma avaliação técnica ou metodológica para e implementação do Moodle no serviço de hospedagem, nem alguma formação prévia quanto ao uso deste recurso para gestores, coordenadores, professores ou alunos.

Pelo fato de utilizar, há muitos anos, em minhas práticas pedagógicas o AVA em suporte às aulas presenciais, de forma híbrida, esse grupo de alunos já tinha alguma ambientação com o Moodle. A prática minimizou os impactos de uma ambientação compulsória a um novo Ambiente escolar, agora totalmente remoto, que os demais alunos da escola experimentaram.

Para análise da situação, é importante conhecer o contexto social, econômico e acadêmico do grupo em questão. Os praticantes deste estudo foram um professor e 35 alunos matriculados 
no primeiro semestre de 2020 de um curso na modalidade subsequente. O grupo de praticantes possui predominância masculina (91,5\%), idade média de 28 anos, com idades variando de 17 a 58 anos. A escolaridade mínima requerida pelo curso é o Ensino Médio, porém alguns dos alunos cursam, de forma concomitante, o ensino superior em áreas diversas. Cerca de $50 \%$ dos alunos já exercem atividades profissionais e alguns deles são chefes de família.

O percurso metodológico adotado constituiu-se de uma pesquisa no cotidiano gerado a partir da transferência compulsória da educação presencial, tradicionalmente adotada pela escola, para um modelo, em implementação e construção, de ensino remoto em rede. Com abordagens qualitativas e quantitativas, o estudo desenvolveu-se no cotidiano dos praticantes nos ambientes virtuais disponibilizados e em construção. Também foram considerados os dados obtidos a partir de questionários propostos para avaliação dos dispositivos e acessos a rede, bem como a avaliação da percepção dos alunos a todas as mudanças vividas.

Devido à urgência para a implementação do ensino remoto, o AVA foi implementado sem uma avaliação prévia da disponibilidade dos alunos ao digital. O primeiro planejamento foi realizado apenas considerando o uso das facilidades e das aplicações do AVA Subsequente (disponibilização de material, de atividades e interações assíncronas através de devolutivas e fóruns).

Logo após a implementação inicial e a divulgação junto aos alunos, houve um pico de acessos ao AVA, praticamente todos os discentes acessaram o ambiente, buscando conhecer o novo, o inexplorado ambiente remoto de interações educacionais. Mas a realidade ao transcorrer da semana subsequente mostrou-se mais tímida, o acesso à componente curricular reduziu consideravelmente, sem interações em fóruns ou chats. Os praticantes apenas utilizavam o ambiente como repositório de conteúdo e atividades. A execução das atividades planejadas da componente curricular, durante o primeiro mês, demonstrou que 28 dos 35 alunos acessaram o AVA, porém apenas 12 estudantes (43\%) mantinham alguma interação, considerando acessos recorrentes e o desenvolvimento de atividades.

\section{FIGURA 1. O AVA SUBSEQUENTE}




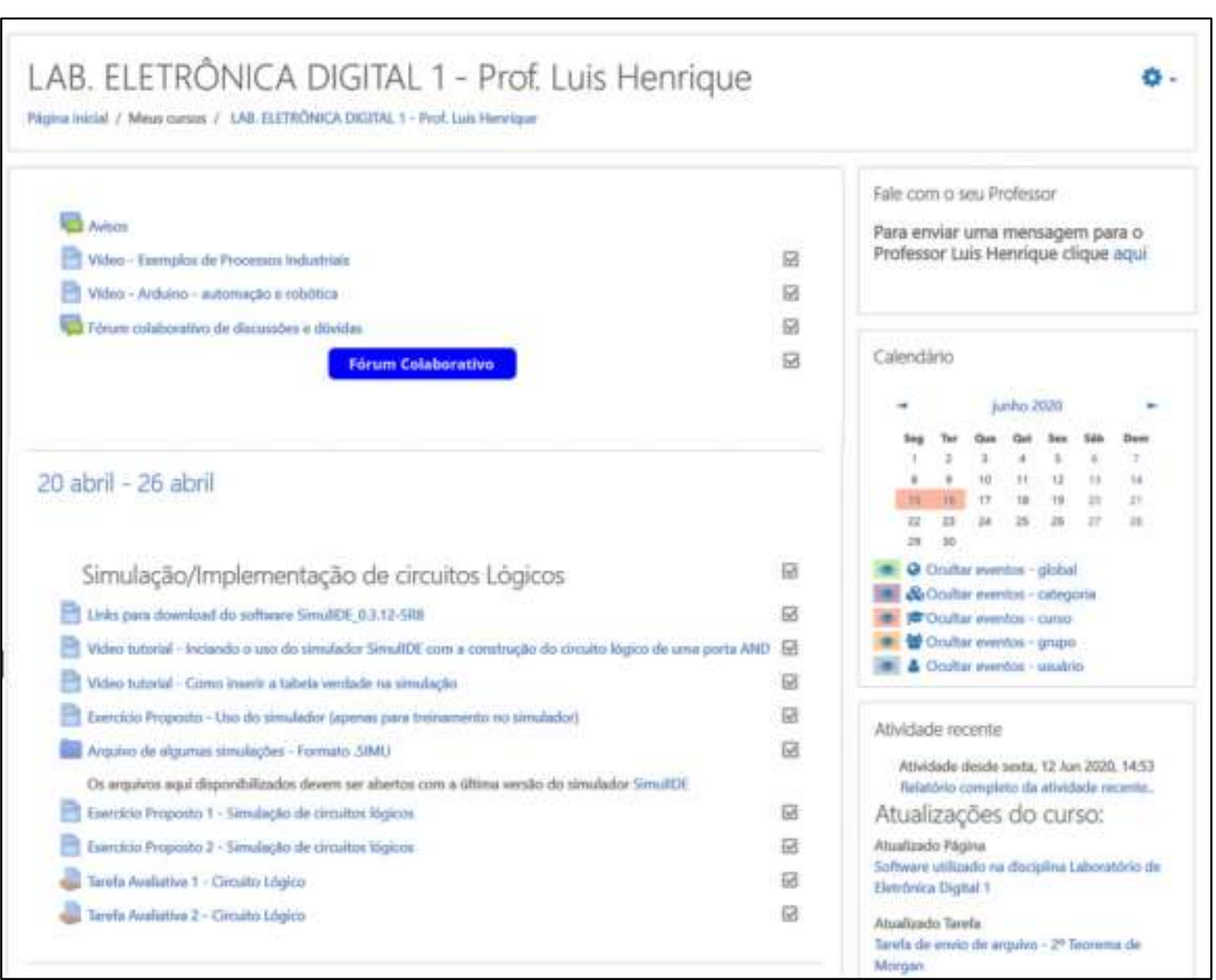

Fonte: Produzido pelo autor.

A baixa interação na estrutura institucional e formal de atendimento remoto da componente curricular levou a um questionamento quanto à dificuldade de acesso ao AVA Subsequente pelo Grupo de WhatsApp. A primeira resposta, quase que em tempo real, de um dos praticantes mencionou a dificuldade de acesso a dispositivos. A partir dessa resposta, foi inevitável repensar a mediação pedagógica para possibilitar interações de qualidade para a construção conjunta da aprendizagem. Pois, como pontuam Okada e Santos:

a mediação pedagógica (cuidadosa e competente) tem um papel de destaque, não somente no sentido de procurar ampliar as interações (mantendo a existência do ambiente), como também, fazer intervenções para garantir conexões de qualidade (desconstrução/ construção/ reconstrução do conhecimento). É importante identificar: [...]Elementos potencializadores: as intenções, os interesses, as expectativas, as experiências prévias dos participantes, as interfaces mais utilizadas, as intervenções que levam a reflexões, as respostas que geram perguntas, as perguntas que conduzem a novas respostas, as articulações tecidas pelos participantes, as produções individuais e coletivas (reflexões, críticas, interpretações, argumentações, desconstruções, reconstruções, alternativas, inovações, criatividade, opiniões próprias), o que pode trazer envolvimento, gerar proximidade e afetividade, trazer aprofundamento e também diversidade para enriquecimento (2003, p.14). 
Desta forma, antes de realizar o planejamento referente ao segundo mês, foram necessários questionamentos com o objetivo de mensurar o acesso a dispositivos e redes a fim de propor mediações pedagógicas mais inclusivas e que despertassem maior interesse e interação. Para os alunos que possuíam acesso à rede, foi disponibilizado um questionário online utilizando a ferramenta formulário do Google Drive. Para aqueles que não possuíam, foi utilizado o método de conversa pelo aplicativo WhatsApp. O questionário versou sobre o interesse em participar do atendimento remoto da componente curricular, a conexão à internet (tipo de acesso e franquia de dados) e o acesso a dispositivos e avaliação do Ambiente Virtual de Aprendizagem quanto ao uso, qualidade e percepções.

Dos trinta e cinco alunos matriculados, vinte e oito $(80 \%)$ relataram interesse em participar das atividades remotas e vinte e quatro $(68,5 \%)$ se dispuseram a responder aos questionamentos sobre dispositivos, sobre disponibilidade de acesso e percepção qualitativa do AVA. Desse grupo, somente a metade tinha acesso de internet com velocidade superior a $10 \mathrm{Mb}$; $37,5 \%$ tinham acesso entre 2 e $10 \mathrm{Mb} ; 4,2 \%$ tinham acesso inferior a $2 \mathrm{Mb}$ e $8,3 \%$ não tinham acesso regular de internet. Neste mesmo grupo, 58,3\% relataram que o acesso utilizado não possuía franquia, 12,5\% relataram franquia entre 10 e $50 \mathrm{~Gb} / \mathrm{mês}, 4,2 \%$ franquia entre 2 e 10 $\mathrm{Gb} / \mathrm{mês}, 4,2 \%$ franquia abaixo de $2 \mathrm{~Gb} /$ mês e $20,8 \%$ relataram não saber informar a franquia. Diante desses dados sobre velocidade de acesso e franquia de dados, podemos concluir que a maioria dos alunos teriam capacidade técnica suficiente para participar de aulas remotas síncronas.

Em relação ao acesso a dispositivos, dos vinte e quatro alunos que responderam aos questionamentos, todos tinham acesso a algum dispositivo para o acesso à internet. Vinte alunos $(83,3 \%)$ possuíam acesso via smartphones, catorze $(58,3 \%)$ possuíam ou tinham o acesso via notebooks ou a PC. Dez alunos relataram que possuíam acesso tanto ao smartphone quanto ao computador pessoal. Neste cenário, todos tinham acesso a algum dispositivo para conexão às redes.

Comparando os dados obtidos com os da Pesquisa Nacional por Amostra de Domicílios Contínua - PNAD/2018, no estado do Rio de Janeiro, considerando apenas os domicílios que possuem algum acesso à internet, 54,0\% deles acessam com a utilização de um computador, enquanto 99,2\% dos domicílios utilizam o telefone móvel celular para este acesso (IBGE, 2018). Consultando o PNAD/2017, observa-se que $82,5 \%$ das pessoas de 10 anos ou mais de idade possuem um telefone celular para uso pessoal (IBGE, 2017).

Quanto as perguntas sobre o AVA, 21 alunos dos alunos (87,5\%) afirmaram estar participando do AVA. Do grupo de 24 alunos que participaram da pesquisa, 8 alunos $(33,3 \%)$ 
avaliaram o AVA como muito bom; 6 alunos (25\%) como bom; 8 alunos (33,3\%) como regular; 1 aluno $(4,2 \%)$ como ruim e 1 aluno $(4,2 \%)$ como muito ruim.

As narrativas apresentadas pelos praticantes evidenciaram fatores positivos da utilização de um Ambiente Virtual de Aprendizagem quanto a usabilidade e recursos como apontaram três alunos:

O site é bom, porem ele é bom como um complemento do que é dado em sala de aula. Acho que mesmo após a pandemia poderiam utilizar o site como um suporte para o aluno, no entanto, dentro dessa situação da pandemia é complicado utilizar somente o site como fonte de estudos" (Aluno 1).

A plataforma funciona bem, é de fácil entendimento e utilização. Acho que ela não deixa a desejar em nenhum ponto. Acho a ideia de ensino a distância boa, porém, e necessário que se tenha mais investimento e suporte aos professores (Aluno 2).

Foi uma ótima iniciativa ter essa plataforma onde tem sido de grande ajuda em um momento tão difícil que estamos vivendo, não podendo ter aula em sala devido a pandemia o AVA está sendo um grande recurso pra conseguirmos continuar estudando e avançar em nosso aprendizado só tenho a agradecer por essa plataforma e aos criadores, pois através de todos vocês tenho agregado muito conhecimento (Aluno 3).

Assim como dois alunos apontaram dificuldades na interação com os professores, pedindo "Mais auxílio dos professores" (Aluno 4) e a necessidade de interação pessoal, mesmo que remota quando pediram a "Implementação para acesso a aulas online" (Aluno 5). Nas falas dos alunos também observou-se a vinculação do uso do ambiente ao momento de excepcionalidade, como a fala do Aluno 1 "Acho que mesmo após a pandemia poderiam utilizar o site" e do Aluno 3 "tem sido de grande ajuda em um momento tão difícil que estamos vivendo" que vincularam o uso do ambiente ao momento de excepcionalidade.

$\mathrm{Na}$ realização do planejamento do segundo mês, foram considerados todos os dados obtidos no questionário e nas interações com os alunos. Desta forma, foi alterada a dinâmica de utilização de recursos utilizados nas práticas da componente curricular para um formato mobile, mais apropriado ao uso dos Smartphones. Manteve-se o uso do AVA Subsequente (disponibilização de material, de atividades e interações assíncronas através de devolutivas e fóruns), porém com maior uso de material responsivo em contraposição aos documentos no formato PDF e com a habilitação e configuração do Moodle para acesso como App Mobile. Também foi proposta aos praticantes a realização de aulas síncronas com o uso de aplicativo de web conferência e a apropriação do grupo de WhatsApp para aplicação como "WhatsAula".

A WhatsAula, de acordo com o conceito desenvolvido por seus criadores, é uma rede composta da "associação entre smartphones, desenho didático, professores, alunos, espaços 
físicos e virtuais de aprendizagens" (ALVES; PORTO; OLIVEIRA, 2018, p. 168). Em nosso cotidiano, esta rede foi utilizada para a inclusão de todos os praticantes, a partir do encaminhamento de materiais relativos às aulas síncronas, integrando os alunos sem acesso às aulas e/ou ao AVA e, principalmente, como espaço interativo e colaborativo de discussões e atendimento.

Com interação assíncrona, o primeiro aluno envia mensagens de texto e tira fotos para apresentar suas dúvidas. O segundo aluno tira fotos, grava áudios e escreve mensagens para possibilitar a sua comunicação com o grupo. E o professor interage com os alunos respondendo, comentando, contribuindo com os materiais recebidos para consolidar a mediação. Tantos e diferentes usos do aplicativo de mensagens para a troca de vídeos, fotos, textos e arquivos, que podem ser feitas de qualquer lugar para qualquer lugar em tempo real, para interações síncronas e/ou assíncronas, uma transformação tecida no seio da cibercultura que é capaz de dinamizar intensamente as redes (SANTOS, R; CARVALHO; MADDALENA, 2017).

Outro recurso utilizado, em conjunto com os demais, foi a metodologia de aulas síncronas, inicialmente planejadas, considerando a transposição da explanação oral com uso de recursos de apresentação. No desenvolvimento das aulas expositivas, a interação dos praticantes foi tão intensa que o espaço acabou por se tornar uma tela em branco, constituindo-se de um espaço aberto para a interação e para a construção de atividades colaborativas a partir das demandas dos praticantes. A web conferência passou a ser realizada de duas formas, a primeira através de uma câmera de um smartphone preso em um suporte e folhas em branco que eram preenchidas a partir da interação e do desenvolvimento de atividades e de necessidades coletivas. A outra através do uso de softwares simuladores de acesso livre e gratuito e de aplicações e ferramentas digitais web e mobiles usados para aproximar as aulas a uma prática profissional simulada de aplicações reais. Criando, desta forma, múltiplas interfaces que

incorporam os aspectos comunicacionais e pedagógicos, bem como a emergência de um grupo-sujeito que aprende enquanto ensina e pesquisa e pesquisa e ensina enquanto aprende. A educação online e seus dispositivos se configuram como espaços formativos de pesquisa e prática pedagógica onde são contempladas a pluralidade discursiva das narrativas e experiências pessoais, profissionais e acadêmicas dos sujeitos (OKADA; OKADA; SANTOS, 2008, p. 9).

FIGURA 2. WEB CONFERÊNCIAS DESENVOLVIDAS
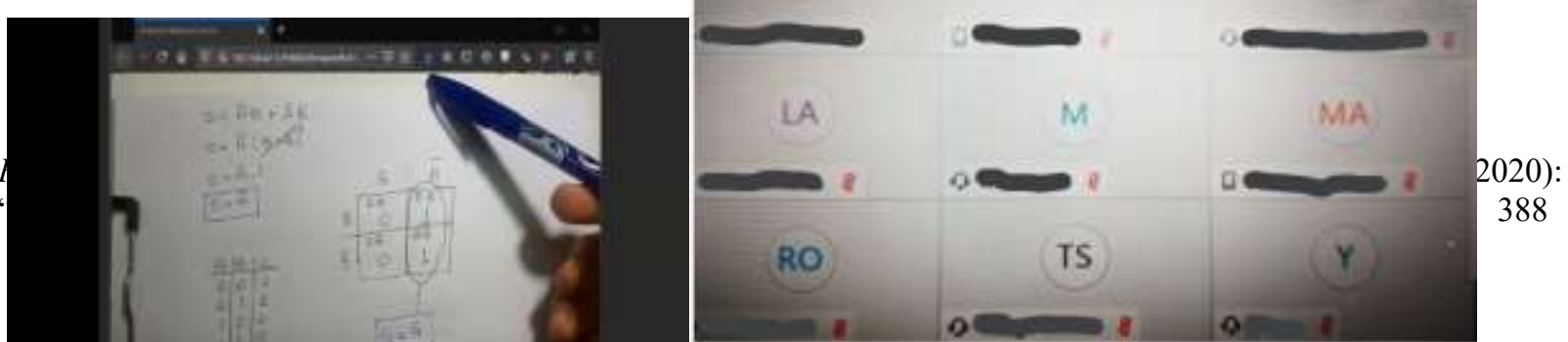


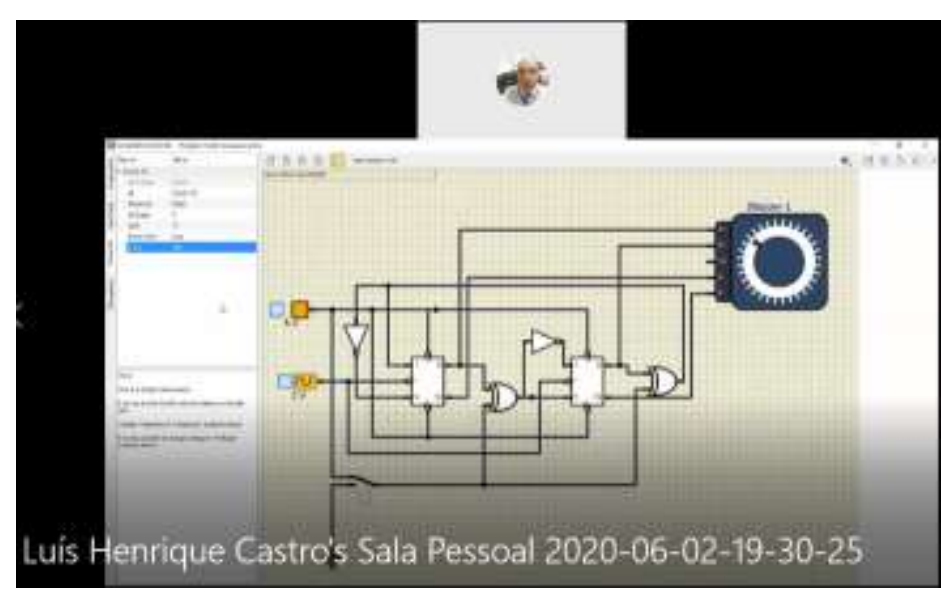

Fonte: Produzido pelo autor.

O material gerado nas aulas remotas síncronas foi digitalizado e todos os arquivos e documentos foram encaminhados para os alunos por mensagens. Visando a integração de todas as interfaces, este material foi, sistematicamente, disponibilizado no AVA Subsequente e enviado através do aplicativo WhatsApp. Com o acesso de todos os praticantes não só ao material da componente curricular e ao material desenvolvido nas aulas remotas síncronas disponibilizados no AVA e no WhatsApp, mas também com a motivação proporcionada pelos encontros professor-alunos presenciais mediados pelo digital, as interações aumentaram significativamente, de acordo com o afirmado por Ribeiro, Carvalho e Santos, que

pensarfazer educação online requer participação ativa de todos os envolvidos no processo formativo, prática educativa arquitetada em sintonia com as práticas ciberculturais, requer que o docente esteja aberto ao outro, articular a interlocução de todos com todos, trazer diferentes fontes de referências e de linguagens e lançar mão de múltiplos meios para potencializar a aprendizagem (2018, p. 11).

Também se verificou um acréscimo numérico de acessos e da qualidade das interações dos praticantes com acesso a esta rede. Os alunos passaram a participar ativamente no fórum colaborativo e a enviar as atividades. Com as múltiplas redes os praticantes soltaram suas vozes, suas narrativas, suas imagens, suas oralidades, e com esta vivência podemos dizer que a docência continua sendo vivenciada (SANTOS, 2019).

Com base na estrutura de múltiplas redes, pensamos e propusemos as "ambiências híbridas" (CARVALHO, 2015, p. 58), ou seja, hibridizamos diferentes mídias/interfaces/artefatos para compor as nossas práticas, tornando-as mais aberto para a 
tessitura do conhecimento em rede e com mais plasticidade para estruturar as ambiências do processo de aprendizagem-ensino.

Como Santos salienta:

Ambiências formativas são as situações de aprendizagem cocriadas nos espaçostempos híbridos em que se articulam os ambientes físicos e digitais (sala de aula presencial, ambientes virtuais de aprendizagem e redes sociais). Uma ambiência formativa é o complexo enredamento onde se dinamizam diversas possibilidades de produção intelectual, de invenção, de constituição de rastros onde um coletivo assume, explicita e reinventa seu processo de formação (2015, p. 40).

Já as "ambiências híbridas" são espaços organizacionais vivos, formativos e híbridos (presencial/online), que envolvem e tornam a sala de aula mais receptível/flexível para os estudantes, viabilizando cocriações entre professor-estudantes/estudantes-estudantes (CARVALHO, 2015). Essa noção visa possibilitar o aprendente a interagir, discutir com o coletivo, manipular e criar seus próprios conteúdos/artefatos, convidar o outro para dialogar e colaborar com o produto criado, além de compartilhar a coautoria em rede. É possível perceber como os alunos executam a atividade, compartilham os caminhos e constroem de forma colaborativa nos diálogos apresentados de forma assíncrona no Fórum:

Professor: Vamos discutir até onde este contador conta... Responda um número de 00 a 99 e justifique. Se concordar diga que concorda... e justifique se discordar apresente um novo número e uma justificativa.

Aluno 1: Acredito que ele conte até 59. Porque a parte superior reseta quando chega em 0110 (6), e a inferior 1010 (10).

Aluno2: Exatamente, o contador vai de 0 á 59. na primeira parte resetando quando tem a combinação 0110. na segunda resetando em 1010.Consegui a resposta fazendo no Simulador.

Aluno 3: Esse é um contador de módulo 60 (0 até 59), o primeiro display reseta no estado 110 (a última saída do primeiro contador é indiferente porque ele reseta antes de 1000) e o segundo display reseta em 1010. Acredito que é usado para contar minutos ou segundos.

Aluno 4: Concordo, o contador vai de 0 a 59. O primeiro display reseta na combinação 0110 e na segunda reseta em 1010. Consegui a resposta também utilizando o simulador!

As participações dos alunos no Fórum colaborativo, como "acredito que ele conte até 59", “exatamente, o contador vai de 0 a 59", "Esse é um contador de módulo 60" e "consegui a resposta também utilizando o simulador!”, mostram interações alunos-alunos. Essa interação propiciou "desdobramentos para o processo formativo, o uso de meios comunicacionais e artefatos culturais em rede na prática educativa" (RIBEIRO, CARVALHO e SANTOS R. 2018, p. 11) 
favorecendo a construção coletiva do conhecimento e da autonomia, quando o praticante conclui, a partir das interações, que "[...] Acredito que é usado para contar minutos ou segundos". A escolha de utilização recorrente dos fóruns partiu da

necessidade de criar espaços para promover conversas elaboradas e densas, para que o(a) s praticantes pesquisado(a)s exponham suas reflexões, tragam seus dilemas, inquietações, práticas e experiências no partilhar coletivo, discutindo uns com os outros, confrontando suas certezas e (re)construindo outras em vista do novo que se apresenta, que afeta e altera (SANTOS, R; CARVALHO; MADDALENA, 2017, p. 200).

Considerando a execução das atividades planejadas da componente curricular durante o segundo mês, observou-se uma participação média de 19 alunos nas aulas remotas semanais por web conferência, de 18 alunos no AVA Subsequente e 24 alunos no WhatsApp.

Com as variadas formas de acesso, durante este segundo mês, houve um aumento das interações nas plataformas em termos quantitativos e qualitativos. $\mathrm{O}$ contato frequente entre professor-aluno, aluno-professor, aluno-aluno, de forma geral foi o grande desafio, a meta a ser alcançada, como afirmam Okada e Santos:

O grande desafio da mediação pedagógica é gerenciar a complexidade entre os elementos e os seus feixes de interações. O mediador define inicialmente a estrutura do ambiente (conteúdo, interfaces, design, atividades...). Nesta estrutura inicial, são definidos quais os canais de comunicação que estarão disponíveis e assim, os participantes poderão escolher onde interagir.

Para que o ambiente seja um organismo vivo, é fundamental que existam interações entre os participantes. São os feixes de interações entre os participantes que podem ampliar ou atenuar o ambiente e manter a sua existência. E, dependendo das relações entre componentes (aspectos técnicos, quantidade e qualidade das mensagens, ...) o ambiente pode se expandir, ou então, se reduzir (2003, p.13).

No início do terceiro mês, fez-se necessária uma avaliação da adesão e da percepção dos alunos quanto às aulas remotas. Desta forma, foi, novamente, disponibilizado um questionário online, utilizando a ferramenta formulário do Google Drive. Para aqueles que não possuíam, foi utilizado o método de conversa pelo aplicativo WhatsApp. O questionário versou sobre o a avaliação das aulas remotas da componente curricular de forma quantitativa e qualitativa.

Dos 24 alunos que participaram deste novo questionário, 22 alunos $(91,7 \%)$ afirmaram que estão participando das aulas remotas. Desse universo de alunos que participaram das aulas remotas a avaliação atribuída foi: 50\% - Muito bom; 22,7\% Bom; e 27,3\% Regular. No espaço de resposta livre destinado a comentário, pedido ou sugestão com relação às aulas remotas, foram registradas as respostas apresentadas a seguir:

Aluno 1: Peço que mais professores façam vídeo aulas, temos vídeo aulas apenas com um professor. 
Aluno 2: Agradeço ao Professor pela disponibilidade das aulas online e gostaria que os demais, caso possível, também seguissem o mesmo padrão um espaço que podemos tirar dúvidas e conversar com os professores.

Aluno 3: Tem sido ótimas aulas, não substitui a interação dentro de uma sala de aula, mas tem sido muito boa

Aluno 4: Maior interação com os alunos.

Aluno 5: Elas são muito boas, pois auxiliam no entendimento da matéria e na parte de tirar as dúvidas.

Aluno 6: As aulas são boas, e os professores se esforçam, mas cada aluno tem uma particularidade, eu por exemplo não consigo aprender direito com esse modelo de ensino, e acredito que eu me formaria um técnico ineficaz ao fim do curso com essa metodologia.

Aluno 7: Bom eu só posso elogiar o professor por tomar a iniciativa de vir conversar com a turma com a possibilidade de dar a matéria através de vídeo aulas, o que ajuda muito no entendimento da matéria, aos demais professores deveriam seguir o mesmo exemplo.

Aluno 8: Um técnico ineficaz ao fim do curso com essa metodologia.

Aluno 9: Que pelo menos $1 \mathrm{hr}$ na semana seja disponibilizado uma aula específica para somente resolução de exercícios passados.

Aluno 10: Que tenha mais aulas com outros professores e não só com apenas um.

As narrativas apresentadas colocam em evidência a importância da interação real, mesmo que remota e mediada digitalmente, de Professor-Aluno, de Aluno-Professor e de Aluno-Aluno. Um momento de ver e perceber o outro de forma plena sob a compreensão da interação humana. Estruturando a narrativa da necessidade do espaço físico sala de aula e do ser humano professor nas interações educacionais. Afinal a construção do conhecimento só pode ser efetiva no contato franco, pleno e contínuo entre os praticantes.

A percepção dos alunos após 60 dias de ensino remoto foi registrada com as respostas atribuídas em mais uma conversa que iniciou com o questionamento do professor.

Professor: Com relação ao atendimento remoto da escola, o que você mais gostou e o que você menos gostou?

Aluno 1: Interação e acesso aos materiais / professores que não respondem.

Aluno 2: Possibilidade de acessar o material em qualquer momento / a falta de suporte para reuniões online através de videoconferência.

Aluno 3: Achei uma iniciativa muito boa por parte dos professores.

Aluno 4: Eu gostei do contato mais próximo com os professores como se estivéssemos em uma sala de aula normal, coisa que auxilia no aprendizado. 
Aluno 5: Gosto do esforço dos professores, porem eu n consigo aprender direito com essa metodologia, minha opinião e que se deveria esperar para termos aulas presenciais.

Aluno 6: A parte negativa seria o acúmulo de tarefas em algumas disciplinas.

Aluno 7: Não sei dizer, por enquanto a qualidade não é das melhores, mas é aceitável por causa que os próprios professores também precisaram se adaptar.

Aluno 8: Por eu ter fácil acesso à internet não possuo problemas com o acesso ao conteúdo. Porém a falta de interação com os professores dificulta o entendimento de questões mais complicadas.

Aluno 9: Falta suporte aos professores para confeccionar um conteúdo didático, prático e de qualidade. Também a necessidade de uma sala de reuniões na própria plataforma AVA.

Aluno 10: Bom que todos que utilizam ficam à vontade, porem nem todos tem acesso, isso complica.

Aluno 11: Gostei bastante, não tenho o que discordar.

Aluno 12: Bom saber que o site traz um conteúdo que em muitas vezes não dá pra se ter escrito em sala de aula, e assim se ter uma base para se estudar em caso de provas, é válido como um complemento do que é dado em sala de aula.

As conversas com os alunos apontam pontos positivos e negativos do atendimento remoto, demonstrando a percepção dos alunos desse cotidiano mediado pelo digital em rede e convergem em três pontos: na precisão de interação entre os praticantes, na urgência do acesso universal às redes e da necessidade de formação de docentes e demais profissionais da educação. Com base nas percepções dos alunos, continuaremos a replanejar, a readequar e a customizar o desenho didático, utilizando múltiplos ambientes de aprendizagem para a construção de um espaço organizacional inclusivo, vivo e formativo que torne o espaço educativo "mais receptível/flexível para os estudantes, tanto no desenvolvimento de atividades, quanto nas situações de aprendizagem e na constituição de novos arranjos comunicacionais, que viabiliza o entrelaçamento de cocriações formativas” (SANTOS, R; RIBEIRO; CARVALHO, 2019).

\section{REFLETINDO SOBRE AS PRÁTICAS VIVIDAS}

Após quase três meses de convivência, nesse novo processo de interações remotas e aprendizagens reais, não temos a pretensão de apresentar uma análise conclusiva deste estudo, já que ele ainda está em desenvolvimento. No entanto, podemos registrar algumas das percepções 
vividas no cotidiano desse período de isolamento social, tão necessário como medida de contenção da pandemia da COVID-19.

Primeiramente, apontamos a importância de um levantamento preliminar dos limites reais de acesso a dispositivos e redes de todos os partícipes. Podemos apontar alguns caminhos válidos para realizá-lo, entre eles está o questionário online, as consultas em aplicativos de mensagens ou os contatos diretos por telefone fixo ou móvel. Os dados coletados devem embasar a escolha das soluções tecnológicas para a aprendizagem com o objetivo de contemplar todos os praticantes, com as suas diferenças e limitações de acesso a dispositivos e redes.

Outro fator fundamental é o conhecimento prévio e a empatia dos alunos aos aplicativos em rede. A predisposição dos usos facilita a ambientação e a integração com todos os praticantes, favorecendo a interação regular e de qualidade nos ambientes e redes. Desta forma, a escolha da interface digital a ser utilizada deve contemplar a opinião dos praticantes para que possa alcançar toda a sua potencialidade nos campos comunicacional e pedagógico.

A bricolagem de redes e de ambientes de aprendizagem deve ser considerada com a intenção de alcançar a interação do aluno, principalmente aquele que tem a limitação de acesso a dispositivos e/ou redes como realidade. Diversas metodologias e interfaces favorecem uma maior possibilidade de interação e imersão dos praticantes no ensino remoto. Nesse cotidiano, foram usados o Ambiente Virtual de Aprendizagem Moodle, o aplicativo de mensagens WhatsApp e algumas plataformas gratuitas de conferências web com as intencionalidades de incluir todos os praticantes, individualmente ou em grupo, fomentar a autoria coletiva e possibilitar um espaço para trocas e construções. Assim, procuramos arquitetar e criar ambiências formativas, autorais e abertas que foram sendo cocriadas no processo ensinar e aprender e que podem ser democratizadas se o planejamento docente considerar o uso do smartphone, dos aplicativos de mensagens e de web conferências, formando uma rede hibrida para a construção coletiva do conhecimento.

O objetivo do atendimento remoto, proposto pela instituição está sendo alcançado com a interação da maioria dos alunos da componente curricular nos diversos Ambientes Virtuais de Aprendizagem gerando através de redes de significados e relações o conhecimento. Nessas interfaces o conhecimento emerge a partir das conexões e interações em rede. Nessa perspectiva, para atingirmos as competências, habilidades e atitudes imprescindíveis para a formação do aluno também precisamos interagir uns com os outros presencialmente. Cabe ressaltar que o atendimento remoto possui suas potencialidades comunicacionais e educativas, mas não substituirá as aulas presenciais que precisarão ser retomadas após este tempo de pandemia. 


\section{REFERÊNCIAS}

ALVES, N.; OLIVEIRA, I. B. Pesquisa nos/dos/com os cotidianos das escolas: sobre redes de saberes. Petrópolis: DP et al, 2008.

ALVES, A., PORTO, C.; OLIVEIRA, K. Educação online mediada pelo WhatsApp: mapeando rastros e controvérsias de alunos à luz da teoria ator-rede. In: Rev. Diálogo Educacional, Curitiba, v. $18, \quad$ n. $56, \quad$ p. 164-185, jan./mar. 2018. Disponível em: $<$ https://periodicos.pucpr.br/index.php/dialogoeducacional/article/view/23547>. Acesso em 10 jun. 2020.

BACICH, L.; TANZI NETO, A.; TREVISANI, F. M. (Org.). Ensino Hibrido: personalização e tecnologia na educação. Porto Alegre: Penso, 2015.

BRASIL. Despacho do Ministro da Educação. Brasília: Diário Oficial da União. Publicado em 18 de outubro de 1996, seção 1, p. 32.

. Ministério da Educação - Conselho Nacional de Educação - Conselho Pleno. Parecer CNE/CP n ${ }^{\circ}$ 5/2020 - Reorganização do Calendário Escolar e da possibilidade de cômputo de atividades não presenciais para fins de cumprimento da carga horária mínima anual, em razão da Pandemia da COVID-19. Disponível em: $<$ http://portal.mec.gov.br/index.php?option=com_docman\&view $=$ download\&alias $=145011$ pcp005-20\&category_slug=marco-2020-pdf\&Itemid=30192 >. Acesso em 10 jun. 2020.

CARVALHO, F. S. P. Atos do Currículo na Educação Online. Rio de Janeiro, 2015. Dissertação (Mestrado em Educação) - ProPed/Uerj.

CERTEAU, M. A invenção do cotidiano: vol.1. Artes de fazer. Petrópolis: Vozes, 2014.

CGI.br/NIC.br. Centro Regional de Estudos para o Desenvolvimento da Sociedade da Informação (Cetic.br), Pesquisa sobre o Uso das Tecnologias de Informação e Comunicação nos domicílios brasileiros - TIC Domicílios, 2018. Disponível em: $<$ https://cetic.br/pesquisa/domicilios/>. Acesso em 14 jun. 2020.

IBGE. Pesquisa Nacional por Amostra de Domicílios (PNAD) 2018. Disponível em: $<$ http://www.ibge.gov.br>. Acesso em 10/06/2020.

. Pesquisa Nacional por Amostra de Domicílios (PNAD) 2017. Disponível em: $<$ http://www.ibge.gov.br>. Acesso em 10/06/2020.

LÉVY, P. Cibercultura. São Paulo: Editora 34, 1999.

OKADA, A.; OKADA, S.; SANTOS, E. (2008). CoLearn: ciberconferência e cibermapeamento para aprendizagem colaborativa aberta em cibercomunidades. In: II Simpósio Nacional da ABCiber - Associação Brasileira de Pesquisadores em Cibercultura. São Paulo: ABCIBER2008, 2008. 
; SANTOS, E. A construção de ambientes virtuais de aprendizagem: por autorias plurais e gratuitas no ciberespaço. In: Reunião Anual da Associação Nacional de Pós-Graduação e Pesquisa em Educação, XXIII, Poços de Caldas: ANPED, 2003.

PRETTO, N. Reflexões: ativismo, redes sociais e educação. Salvador: EDUFBA, 2013.

RIBEIRO, M. R. F.; CARVALHO, F. S. P.; SANTOS, R. Ambiências híbridas-formativas na educação online: desafios e potencialidades em tempos de cibercultura. In: Revista Docência e Cibercultura. Rio de Janeiro: 2018. Disponível em: <https://www.epublicacoes.uerj.br/index.php/re-doc/article/view/30589>. Acesso em 10 jun. 2020.

SANTOS, E. EAD, palavra proibida. Educação online, pouca gente sabe o que é. Ensino remoto, o que temos para hoje. Mas qual é mesmo a diferença? \#livesdejunho... Disponível em: $<$ https://www.e-publicacoes.uerj.br/index.php/re-doc/announcement/view/1119>. Acesso em 21 jun. 2020.

. Pesquisa-formação na cibercultura. Teresina: EDUFPI, 2019.

Educação online para além da EAD. In: Actas do X Congresso Internacional Galego-

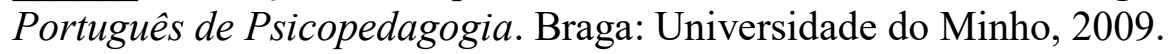

SANTOS, R.; RIBEIRO, M. R. F.; CARVALHO, F. S. P. Educação Online: aprenderensinar em rede. In: SANTOS, E. O.; PIMENTEL, M.; SAMPAIO, F. F. (org.). Informática na Educação: cultura, sociedade, histórias e políticas. Porto Alegre: Sociedade Brasileira de Computação, 2019. n. p. (Série Informática na Educação, v.1). Disponível em: $<$ https://informaticanaeducacao.uniriotec.br/2017/10/25/educacao-online-aprenderensinar-emrede/>. Acesso em 21 jun. 2020.

; CARVAlHO, F. S. P.; MADDALENA, T. L. Conversas ubíquas via WhatsApp: ambiências formativas multirreferenciais. In. PORTO, C.; OLIVEIRA, K. E.; CHAGAS, A. (orgs.): Whatsapp e educação: entre mensagens, imagens e sons. Ilhéus, Bahia: Ed. UESC, 2017. p. 197-218.

. Formação de Formadores e Educação Superior na cibercultura: itinerâncias de Grupos de Pesquisa no Facebook. 2015. 183 f. Tese de Doutorado em Educação - Faculdade de Educação, Universidade do Estado do Rio de Janeiro, Rio de Janeiro, 2015.

; SANTOS, E. Cibercultura: redes educativas e práticas cotidianas. In: Revista Eletrônica Pesquiseduca v. 04, n. 07. p.159-183, jan.-jul. 2012. Disponível em: $<\mathrm{http}$ ://periodicos.unisantos.br/index.php/pesquiseduca/article/view/226>. Acesso em 21 jun. 2020.

SERRES, M. Hominescências: o começo de uma outra humanidade. Rio de Janeiro: Bertrand Brasil, 2003.

SIQUEIRA, A. O lado sensível da concretude do mundo. In: ALMEIDA, A. M.; KNOBB, M.; ALMEIDA, M. C. Polifônicas Ideias: por uma ciência aberta. Porto Alegre: Sulina, 2003. 
UNESCO - United Nations Educational, Scientific and Cultural Organization. COVID-19 Educational Disruption and Response. UNESCO Website. Disponível em: $<\mathrm{https}$ ://en.unesco.org/covid19/educationresponse>. Acesso em 10 jun.2020.

i Mestre em Ensino de Física pela UNIRIO, Graduado em Tecnologia em Sistemas da Computação pela UFF,
Graduado em Licenciatura em Técnicas Industriais pela FABES. Atua profissionalmente como Professor efetivo na
Escola Técnica Ferreira Viana (ETEFV) vinculada à Fundação de Apoio à Escola Técnica do Estado do Rio de
Janeiro (FAETEC). Vinculado à Fundação de Estudos do Mar (FEMAR). Membro do Grupo de Pesquisa Educiber
(UERJ). Rio de Janeiro, Brasil. E-mail: luishmcastro@gmail.com. ORCID: https://orcid.org/0000-0001-6149-7047.

${ }^{i i}$ Formada em Letras e Pedagogia. Doutora e Mestre em Educação pela UERJ. Professora Adjunta do Departamento de Formação de Professores da Faculdade de Educação da Baixada Fluminense (FEBF-UERJ). Professora do Programa de Pós-Graduação em Educação- Proped na Linha de Pesquisa Cotidianos, Redes Educativas e Processos Culturais. Professora do Programa de Pós-Graduação em Educação, Cultura e Comunicação em Periferias Urbanas (PPGECC) na Linha de Pesquisa:Educação, Comunicação e Cultura. Vice-coordenadora do GPDOC - Grupo de Pesquisa Docência e Cibercultura. Líder do EduCiber ( Grupo de Pesquisa Educação e Cibercultura) Parecerista Ad Hoc do GT 16, Educação e Comunicação, da ANPED. Parecerista Ad Hoc do ENDIPE ( Encontro Nacional de Didática e Práticas de Ensino). Atuou 26 anos como professora da Educação Básica no Município de Duque de Caxias, RJ. Atua na área de Educação, com destaque nas seguintes áreas: Educação. Pesquisa. Cibercultura. Formação de Professores. Currículo. Periferias Urbanas. Educação Básica. Rio de Janeiro, Brasil. E-mail: rose.brisaerc@gmail.com. ORCID: https://orcid.org/0000-0003-0479-1703.

iii Adotamos o uso dos termos espaçostempos, dentrofora, entre outros, escritos de forma diferenciada, pois nos inspiramos no referencial teórico de Alves (2008) sobre as pesquisas nos/dos/com os cotidianos. Para a autora: "a junção de termos e a sua inversão, em alguns casos, quanto ao modo como são 'normalmente' enunciados, nos pareceu, há algum tempo, a forma de mostrar os limites para as pesquisas nos/dos/com os cotidianos, do modo dicotomizado criado pela ciência moderna para analisar a sociedade”. (ALVES, 2008, p.11).

${ }^{\text {iv }}$ Esse termo é utilizado por Certeau (2009) para aqueles que vivem e se envolvem dialogicamente com as práticas do cotidiano. Iremos utilizá-lo neste trabalho por concordarmos com o autor, para quem: “[...] o enfoque da cultura começa quando o homem ordinário se torna o narrador, quando define o lugar (comum) do discurso e o espaço (anônimo) de seu desenvolvimento" (CERTEAU, 2009, p. 63). 